\title{
Rb1 Protects Endothelial Cells from Hydrogen Peroxide-Induced Cell Senescence by Modulating Redox Status
}

\author{
Ding-Hui Liu, ${ }^{a}$ Yan-Ming Chen, ${ }^{b}$ Yong Liv, ${ }^{a}$ Bao-Shun Hao,,${ }^{a}$ Bin Zhou,,${ }^{a}$ Lin Wu, ${ }^{a}$ Min Wang, ${ }^{a}$ \\ Lin Chen, ${ }^{a}$ Wei-Kang Wu, ${ }^{c}$ and Xiao-Xian QIAN ${ }^{*, a, c}$ \\ ${ }^{a}$ Department of Cardiology, The Third Affiliated Hospital of Sun Yat-sen University; ${ }^{b}$ Department of Endocrinology, The \\ Third Affiliated Hospital of Sun Yat-sen University; Guangzhou, Guangdong 510630, China: and ${ }^{c}$ Institute Integrated \\ Traditional Chinese and Western Medicine, Sun Yat-sen University; Guangzhou, Guangdong 510630, China. \\ Received February 12, 2011; accepted April 12, 2011; published online April 15, 2011
}

\begin{abstract}
Senescence of endothelial cells has been proposed to play an important role in endothelial dysfunction and atherogenesis. In the present study we aimed to investigate whether ginsenoside Rb1, a major constituent of ginseng, protects endothelial cells from $\mathrm{H}_{2} \mathrm{O}_{2}$-induced endothelial senescence. While $\mathrm{H}_{2} \mathrm{O}_{2}$ induced premature senescent-like phenotype of human umbilical vein endothelial cells (HUVECs), as judged by increased senescenceassociated $\beta$-galactosidase (SA- $\beta$-gal) activity, enlarged, flattened cell morphology and sustained growth arrest, our results demonstrated that $\mathrm{Rb} 1$ protected endothelial cells from oxidative stress induced senescence. Mechanistically, we found that Rb1 could markedly increase intracellular superoxide dismutase (Cu/Zn SOD/SOD1) activity and decrease the malondialdehyde (MDA) level in $\mathrm{H}_{2} \mathrm{O}_{2}$-treated HUVECs, and suppress the generation of intracellular reactive oxygen species (ROS). Consistent with these findings, Rb1 could effectively restore the protein expression of $\mathrm{Cu} / \mathrm{Zn} \mathrm{SOD}$, which was down-regulated in $\mathrm{H}_{2} \mathrm{O}_{2}$ treated cells. Taken together, our data demonstrate that $\mathrm{Rb} 1$ exhibits antioxidant effects and antagonizes $\mathrm{H}_{2} \mathrm{O}_{2}$-induced cellular senescence.
\end{abstract}

Key words senescence; human umbilical vein endothelial cell; reactive oxygen species; antioxidant

Aging is considered as a high risk factor for cardiovascular diseases, especially for atherosclerosis. ${ }^{1,2)}$ Vascular aging is believed to be associated with pro-oxidant and pro-inflammatory phenotypic and functional changes, which promote the progression of cardiovascular diseases. ${ }^{3)}$

At the cellular level, senescence is a state of permanent growth arrest in which cells are alive and metabolically active for months, but are unresponsive to mitogenic stimuli. ${ }^{4)}$ Free radical-dependent cellular damage theory was developed since 1956 and remains the theory basis of aging. ${ }^{5)}$ Accumulating evidence supports the link between oxidative stress and aging by showing that oxidative stress induces cellular senescence. ${ }^{6-9)}$ Hydrogen peroxide is widely used to achieve oxidative stress-induced premature senescence within a short time period.

Ginsenoside $\mathrm{Rb} 1$ is one of 40 bioactive extracts from ginseng which has been used as tonic remedy in traditional Chinese Medicine for two thousand years. ${ }^{10,11)}$ Previous studies have demonstrated that increased generation of reactive oxygen species (ROS) in the injured vascular can be reversed by $\mathrm{Rb} 1$ treatment which provides a protective effect on the vascular injury. ${ }^{12)}$ Therefore, we postulate that ginsenoside $\mathrm{Rb} 1$ may play a role in protecting vascular cells from senescence through modulating the balance of the antioxidant related enzyme and pro-oxidant related enzyme. To evaluate the protective effects of Rb1, we employed human umbilical vascular endothelial cells (HUVECs) as a model and determined the superoxide dismutase (SOD) and malondialdehyde (MDA) levels in the cells treated by Rb1.

SOD, along with other enzymatic and non-enzymatic antioxidants, plays a pivotal role in preventing cellular damage caused by ROS. It exerts its role through reducing the superoxide radical to form hydrogen peroxide and oxygen. There are three forms of SODs which are designated as $\mathrm{Cu} / \mathrm{Zn}$ SOD (SOD1), mitochondrial Mn-SOD (SOD2), and extracellular SOD (SOD3). ${ }^{13)}$ SOD1, the most extensively studied antioxidant enzyme, is constitutively expressed in all mammalian cells and is localized in the cell cytosol and the nucleus. ${ }^{14)} \mathrm{MDA}$ is a major and stable end product formed during the peroxidation of lipids and is regarded as marker of lipid peroxidation in tissues. ${ }^{15}$ )

Here, we reported that $\mathrm{Rb} 1$ antagonizes $\mathrm{H}_{2} \mathrm{O}_{2}$-induced HUVECs senescence through upregulating endogenous antioxidants SOD and decreasing vascular lipid peroxidation.

\section{MATERIALS AND METHODS}

Chemicals and Reagents Rb1 was purchased from the Division of Chinese Materia Medica and Natural Products, National Institute for the Control of Pharmaceutical and Biological Products, Ministry of Public Health (Beijing, China). Hydrogen peroxide $\left(\mathrm{H}_{2} \mathrm{O}_{2}\right)$ and dimethylsulfoxide (DMSO) were obtained from Sigma (St. Louis, MO, U.S.A.). The reagent kits for the measurement of the levels of MDA and SOD were purchased from Nanjing Institute of Jiancheng Bioengineering (Nanjing, China). 2',7'-Dichlorofluorescein diacetate $\left(\mathrm{H}_{2} \mathrm{DCFDA}\right)$ and TRIzol reagent were obtained from Invitrogen (Carlsbad, CA, U.S.A.). PrimeScript ${ }^{\mathrm{TM}}$ RT reagent Kit and SYBR Premix Ex Taq ${ }^{\mathrm{TM}}$ Kit were obtained from TaKaRa (TaKaRa, Dalian, China). All other reagents used were of analytical grade.

Cell Culture Primary HUVECs were prepared from newborn human umbilical cords within $6 \mathrm{~h}$ by $0.1 \%$ collagenase (Gibco) perfusion as described previously. ${ }^{16)}$ HUVECs were plated into a $0.2 \%$ gelatin-coated cell culture flask and grown in Medium 199 (M199) (Gibco) supplemented with 20\% Fetal Bovine Serum (FBS) (Gibco), 20\% Serum-Free Medium (SFM) (Gibco), 2 mmol/1 glutamine, $60 \mu \mathrm{g} / \mathrm{ml} \mathrm{En-}$ dothelial Cell Growth Supplement (ECGS) (BD) and $5 \mathrm{U} / \mathrm{ml}$ heparin, kept in a humid incubator at $37^{\circ} \mathrm{C}$ in $5 \% \mathrm{CO}_{2}$. Subcultures were obtained by treating cells with $0.05 \%$ trypsinethylenediaminetetraacetic acid (EDTA) solution (Gibco). 
Experiments were conducted on cells with a passage number between passages 2 and 3. The cell type was determined by "cobblestone" cell morphology and by flow cytometric analysis with a monoclonal anti-human CD31 antibody (BD, U.S.A.). More than $99 \%$ of the cells were positive for CD31. The protocol was approved by the Research Committee of the Third Affiliated Hospital of Sun Yat-sen University and conformed to the principles outlined in the Declaration of Helsinki. The parturients enrolled in the current protocol were negative for Human Immunodeficiency Viruses (HIV), Hepatitis B Virus (HBV) and Hepatitis C Virus (HCV) and gave written informed consent to providing their umbilical cord.

Cell Treatment The exponentially growing HUVECs were plated at a cell density of $1 \times 10^{5} /$ well in 6 -well plate and cultured overnight at $37^{\circ} \mathrm{C}$. The next day, the medium was changed with M199 supplemented with 2\% FBS for at least $8 \mathrm{~h}$ to starve the cells. Then the cells were exposed to various concentrations of $\mathrm{H}_{2} \mathrm{O}_{2}$ to induce premature senescence. After $1 \mathrm{~h}$, the medium was replaced with normal medium. Different concentration of Rb1 (10, 20, $40 \mu \mathrm{mol} / \mathrm{l})$ was added in the media $30 \mathrm{~min}$ before the induction of senescence by addition of $\mathrm{H}_{2} \mathrm{O}_{2}$. Finally the cells were harvested in indicated time for Western blot analysis and real-time polymerase chain reaction (PCR).

Senescence-Associated $\boldsymbol{\beta}$-Galactosidase (SA- $\boldsymbol{\beta}$-Gal) Assay To determine the number of senescent cells, senescence-associated $\beta$-galactosidase staining was performed as described previously. ${ }^{17}$ Briefly, cells were washed twice in phosphate buffered saline (PBS) and fixated in $2 \%$ formaldehyde and $0.2 \%$ glutaraldehyde for $5 \mathrm{~min}$ at room temperature, washed twice and incubated for $18 \mathrm{~h}$ at $37^{\circ} \mathrm{C}\left(\right.$ no $\left.\mathrm{CO}_{2}\right)$ with fresh SA- $\beta$-gal staining solution $(1 \mathrm{mg} / \mathrm{ml} 5$-bromo-4-chloro3-indolyl-D-galactoside, $40 \mathrm{mmol} / 1 \mathrm{citric}$ acid/sodium phosphate dibasic at $\mathrm{pH} 6.0,150 \mathrm{mmol} / \mathrm{l} \mathrm{NaCl}, 2 \mathrm{mmol} / 1 \mathrm{MgCl}_{2}$, $5 \mathrm{mmol} / 1 \mathrm{~K}_{3}\left[\mathrm{Fe}(\mathrm{CN})_{6}\right]$ and $\left.5 \mathrm{mmol} / 1 \mathrm{~K}_{4}\left[\mathrm{Fe}\left(\mathrm{CN}_{6}\right)\right] 3 \mathrm{H}_{2} \mathrm{O}\right)$. Light microscopic pictures were taken on an inverted microscope with a $\times 100$ magnification. Senescent cells were identified as blue-stained cells, and a total of 400 contiguous cells were counted to determine the percentage of SA- $\beta$-gal positive cells.

Measurement of Intracellular SOD Activity and MDA Level The MDA level and SOD activity were determined using commercially available kits following the manufacturer's instructions. The results were expressed as units per milligram of protein. The assay for SOD activity was based on its ability to inhibit the oxidation of hydroxylamine by $\mathrm{O}_{2}^{-\cdot}$ produced from the xanthine-xanthine oxidase system. One unit of SOD activity was defined as the amount that reduced the absorbance at $550 \mathrm{~nm}$ by $50 \%$. MDA was measured at a wavelength of $532 \mathrm{~nm}$ by reacting with thiobarbituric acid (TBA) to form a stable chromophoric product. The result was expressed by thiobarbituric acid reactive substances (TBARS).

Real-Time Polymerase Chain Reaction (PCR) Total RNA in HUVECs was isolated using Trizol (Invitrogen, U.S.A.) following the manufacturer's instructions. cDNA was generated by reverse transcript from mRNA using the PrimeScript $^{\mathrm{TM}}$ RT reagent Kit (TaKaRa, Dalian, China) according to the manufacturer's instructions. The SYBR Premix Ex $\mathrm{Taq}^{\mathrm{TM}}$ Kit (TaKaRa, Dalian, China) was then used for real- time PCR reaction. $\beta$-Actin, a housekeeping gene, was used as internal control to account for variations in mRNA loading. The $\beta$-actin (GenBank No. NM_001101.3) primer sequences were: forward 5'-AGC GGG AAA TCG TGC GTG AC-3' and reverse 5' ${ }^{\prime}$ TCC ATG CCC AGG AAG GAA GG3'. The SOD1 (GenBank No. NM_000454.4) primer sequences were: forward 5'-CAA AGA TGG TGT GGC CGA TG-3' and reverse 5' -TTT CCA CCT TTG CCC AAG TCA$3^{\prime}$. Real-time PCR was performed in an ABI 7000 PCR detection system. The thermal cycle condition used for reverse transcription was as follows: $15 \mathrm{~min}$ at $37^{\circ} \mathrm{C}$ and $5 \mathrm{~s}$ at $85^{\circ} \mathrm{C}$. The condition used for real-time PCR was as follows: $30 \mathrm{~s}$ at $95^{\circ} \mathrm{C}, 40$ repeats of $5 \mathrm{~s}$ at $95^{\circ} \mathrm{C}$ and $31 \mathrm{~s}$ at $60^{\circ} \mathrm{C}$, and $1 \mathrm{re}-$ peat of $15 \mathrm{~s}$ at $95^{\circ} \mathrm{C}, 1 \mathrm{~min}$ at $60^{\circ} \mathrm{C}$ and $15 \mathrm{~s}$ at $95^{\circ} \mathrm{C}$.

Western Blotting The cells were lysed with whole cell lysis buffer (KeyGen BioTechonology, Nanjing, China) according to the manufacturer's instructions. Cells lysates were quantified by BCA methods according to the manufacture's instructions (Sangon BioTechonology, Shanghai, China), then resuspended in the sample buffer and boiled for $5 \mathrm{~min}$ at $100{ }^{\circ} \mathrm{C}$. The same amount of protein was electrophoresed on $4-12 \%$ gradient sodium dodecyl sulfate-polyacrylamide gel electrophoresis (SDS-PAGE) gels and transferred onto polyvinylidene difluoride membranes (Millipore, U.S.A.). Membranes were blocked using 5\% nonfat dried milk in TBST for $1 \mathrm{~h}$ at room temperature with gentle shaking, then probed with a rabbit antihuman SOD1 monoclonal antibody (EPITOMICS, U.S.A.) at the dilution of $1: 100000$ or glyceraldehyde-3-phosphate dehydrogenase (GAPDH) primary antibody followed by horseradish peroxidase (HRP)-conjugated goat anti-rabbit immunoglobulin G secondary antibody at the dilution of $1: 10000$. Membranes were developed using the enhanced chemiluminescence detection method (Millipore, U.S.A.), and the signals were quantified using Quantity One Software (Bio-Rad, U.S.A.).

Flow Cytometric Evaluation of ROS Intracellular ROS generation was monitored by flow cytometry using peroxidesensitive fluorescent probe $2^{\prime}, 7^{\prime}$-dichlorofluorescein diacetate $\left(\mathrm{H}_{2} \mathrm{DCFDA}\right.$, Invitrogen). $\mathrm{H}_{2}$ DCFDA is converted by intracellular esterases to $\mathrm{DCFH}$, which is oxidized into the highly fluorescent dichlorofluorescein (DCF) in the presence of a proper oxidant. The cells were loaded with $1 \mu \mathrm{mol} / 1$ $\mathrm{H}_{2}$ DCFDA in serum-free medium at $37^{\circ} \mathrm{C}$ for $30 \mathrm{~min}$ and then washed twice with PBS. Next, the cells were monitored with a flow cytometer (BD, U.S.A.) at an excitation wavelength of $488 \mathrm{~nm}$ and an emission wavelength of $525 \mathrm{~nm}$. ROS was determined by comparing the changes in fluorescence intensity to those of the control.

Statistical Analysis Data were expressed as mean \pm the standard error (S.E.) of the mean (S.E.M.) and analyzed using a LSD analysis. A $p$ value $<0.05$ was considered statistically significant.

\section{RESULTS}

Rb1 Antagonizes $\mathrm{H}_{2} \mathrm{O}_{2}$-Induced HUVECs Senescence $40-100 \mu \mathrm{mol} / 1 \quad \mathrm{H}_{2} \mathrm{O}_{2}$ could effectively induce HUVECs senescence (data not shown), and we chose the concentration of $60 \mu \mathrm{mol} / 1 \mathrm{H}_{2} \mathrm{O}_{2}$ to set up the senescent model. As shown in Fig. 1, based on the SA- $\beta$-gal staining in which positive senescent cells were stained blue, $60 \mu \mathrm{mol} / 1 \mathrm{H}_{2} \mathrm{O}_{2}$ induced 


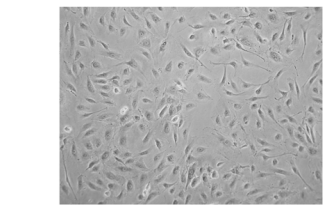

$\mathrm{H}_{2} \mathrm{O}_{2} \mu \mathrm{M} \quad \mathrm{O}$

$\mathrm{Rb} 1 \mu \mathrm{M} \quad \mathrm{O}$

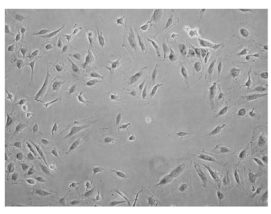

60

0
60

20

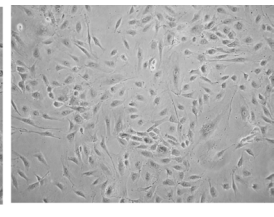

Fig. 1. Rb1 Antagonizes $\mathrm{H}_{2} \mathrm{O}_{2}$-Induced Senescence in HUVECs

HUVECs were pretreated with $\mathrm{Rb} 1$ for $30 \mathrm{~min}$ before the administration of $60 \mu \mathrm{M}$ $\mathrm{H}_{2} \mathrm{O}_{2}$. The medium was replaced with normal medium $1 \mathrm{~h}$ later and cultured for another $24 \mathrm{~h}$. Then the cells were stained for assessment of senescence cells. The cells stained blue were positive senescent cells. Shown were representative pictures from three independent experiments on $2-3$ passaged cells after separate primary cultures with similar results.

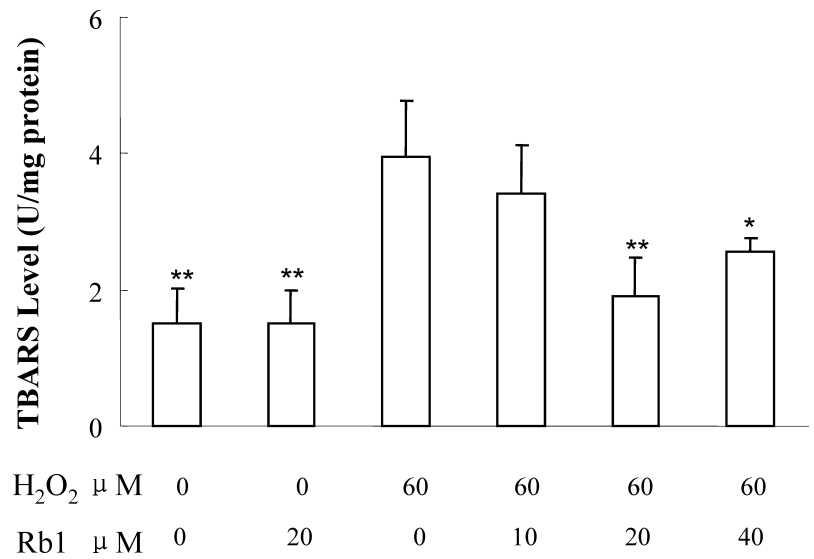

Fig. 2. Rb1 Reduces TBARS (MDA) Level in HUVECs

HUVECs were pretreated with different doses of $\mathrm{Rb} 1$ for $30 \mathrm{~min}$ before the administration of $60 \mu \mathrm{M} \mathrm{H}_{2} \mathrm{O}_{2}$. The medium was replaced with normal medium $1 \mathrm{~h}$ later and cultured for another $24 \mathrm{~h}$. TBARS level was measured and expressed as units per milligram of protein. Values were means \pm S.E.M. from three independent experiments on $2-3$ passaged cells after separate primary cultures. $* p<0.05$, $* * p<0.01$ versus $60 \mu \mathrm{M}$ $\mathrm{H}_{2} \mathrm{O}_{2}$ alone.

the senescence of HUVECs and $20 \mu \mathrm{mol} / 1 \mathrm{Rb} 1$ antagonized the senescence induced by $\mathrm{H}_{2} \mathrm{O}_{2}$ effectively.

Effects of Rb1 on MDA Content and SOD Activity The effects of $\mathrm{Rb} 1$ on lipid peroxidation and endogenous antioxidant preservation were measured. Treatment with $\mathrm{H}_{2} \mathrm{O}_{2}$ caused significant increase in intracellular TBARS level $(p<0.01$ vs. untreated control), while pre-incubation with $\mathrm{Rb} 1 \quad(20,40 \mu \mathrm{mol} / \mathrm{l})$ markedly attenuated the increase $(p<0.05)$ (Fig. 2). As the control, Rb1 alone did not significantly change the TBARS level. Similarly, the SOD activity was comparable between the non-treated control and $\mathrm{Rb} 1$ alone treated group. Compared to control group, treatment with $\mathrm{H}_{2} \mathrm{O}_{2}$ decreased the activity of SOD to $50.4 \pm 6.9 \%$. However, pre-incubation with $\mathrm{Rb} 1(10,20,40 \mu \mathrm{mol} / \mathrm{l})$ significantly increased SOD activity compared with $\mathrm{H}_{2} \mathrm{O}_{2}$ alone treated group $(p<0.01)$ (Fig. 3).

Rb1 Promotes the Expression of SOD1 in HUVECs To evaluate whether $\mathrm{Rb} 1$ plays a role in the reversal of senescence through modulating the redox status, we examined the expression of SOD1 at mRNA level in HUVECs treated by Rb1. Real-time PCR analysis showed that at the time point of $24 \mathrm{~h}$, SOD $1 \mathrm{mRNA}$ in the $60 \mu \mathrm{mol} / 1 \mathrm{H}_{2} \mathrm{O}_{2}$ treated group decreased by 1.99 fold, compared with untreated group $(p<0.01)$. However, SOD1 mRNA increased by $1.54,1.77$, 1.75 fold in $10,20,40 \mu \mathrm{mol} / 1 \mathrm{Rb} 1$ pretreated group respectively, compared with $\mathrm{H}_{2} \mathrm{O}_{2}$ alone treated group $(p<0.01)$

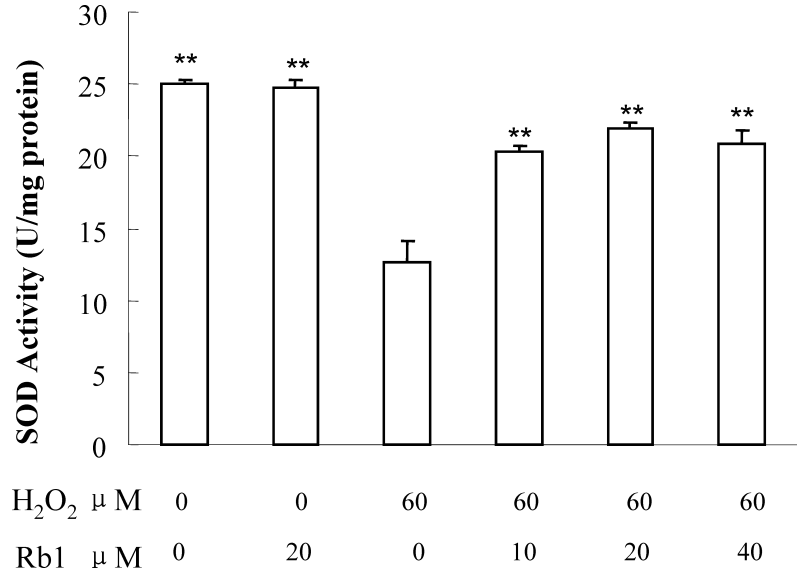

Fig. 3. Rb1 Upregulates SOD Activity in HUVECs

HUVECs were pretreated with different doses of Rb1 for $30 \mathrm{~min}$ before the administration of $60 \mu \mathrm{M} \mathrm{H}_{2} \mathrm{O}_{2}$. The medium was replaced with normal medium $1 \mathrm{~h}$ later and cultured for another $24 \mathrm{~h}$. SOD activity was measured and expressed as units per milligram of protein. Values were means \pm S.E.M. from three independent experiments on $2-3$ passaged cells after separate primary cultures. ** $p<0.01$ versus $60 \mu \mathrm{M} \mathrm{H}_{2} \mathrm{O}_{2}$ alone.

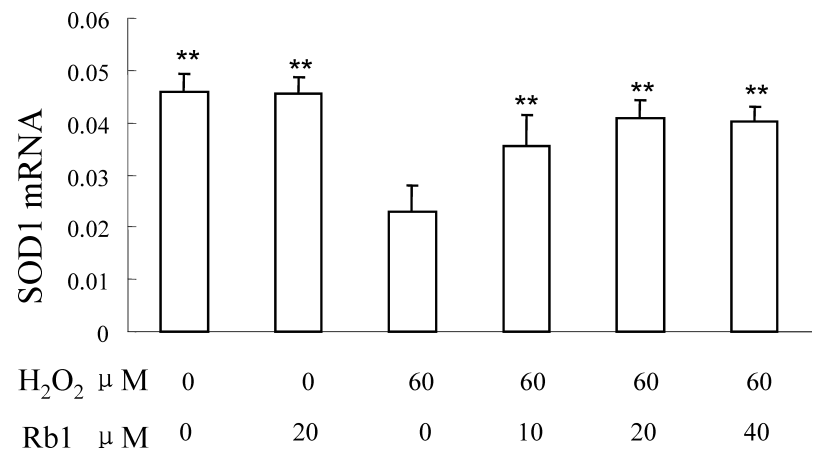

Fig. 4. Rb1 Promotes SOD1 mRNA Expression in HUVECs

HUVECs were pretreated with $10,20,40 \mu \mathrm{M}$ Rb1 for $30 \mathrm{~min}$ before the administration of $60 \mu \mathrm{M} \mathrm{H}_{2} \mathrm{O}_{2}$. The medium was replaced with normal medium $1 \mathrm{~h}$ later and cultured for another $24 \mathrm{~h}$. The mRNA level of SOD1 was measured by real-time PCR and normalized against $\beta$-actin, shown as $2^{-[\mathrm{Ct}(\mathrm{Cu} / \mathrm{ZnSOD})-\mathrm{Ct}(\beta \text {-actin)]. Values were }}$ means \pm S.E.M. from three independent experiments on $2-3$ passaged cells after separate primary cultures. $* * p<0.01$ versus $60 \mu \mathrm{M} \mathrm{H}_{2} \mathrm{O}_{2}$ alone

(Fig. 4). These data suggest that Rb1 upregulates SOD1 mRNA expression in HUVECs. To provide further evidence for this, we examined SOD1 protein level in HUVECs. Western blotting results demonstrated that the level of SOD1 protein reduced in $\mathrm{H}_{2} \mathrm{O}_{2}$ treated group compared to untreated group after 24, 48 and $72 \mathrm{~h}$ incubation (Fig. 5). However, $\mathrm{Rb} 1$ reversed the decreased expression of SOD1 protein in HUVECs treated with $\mathrm{H}_{2} \mathrm{O}_{2}$ in a dose-dependent manner (Fig. 5). As the control, Rb1 alone did not significantly change the expression of SOD1 at either mRNA or protein level. Taken together, these data demonstrate that $\mathrm{Rb} 1$ upregulates the expression of SOD1 in $\mathrm{H}_{2} \mathrm{O}_{2}$ treated HUVECs.

Intracellular Radical Scavenging Ability of Rb1 To confirm whether ROS production is affected as results of the changes of SOD1 activity and expression in the non-treated, $\mathrm{H}_{2} \mathrm{O}_{2}$-treated, and $\mathrm{Rb} 1$-pretreated groups, we measured intracellular ROS level using the ROS-sensitive probe $\mathrm{H}_{2} \mathrm{DCF}$ DA by a flow cytometry. In accordance with the previous results of SOD activity and expression, Rb1 alone did not change the ROS generation. However, compared to the nontreated control group, $60 \mu \mathrm{mol} / 1 \mathrm{H}_{2} \mathrm{O}_{2}$ significantly increased 

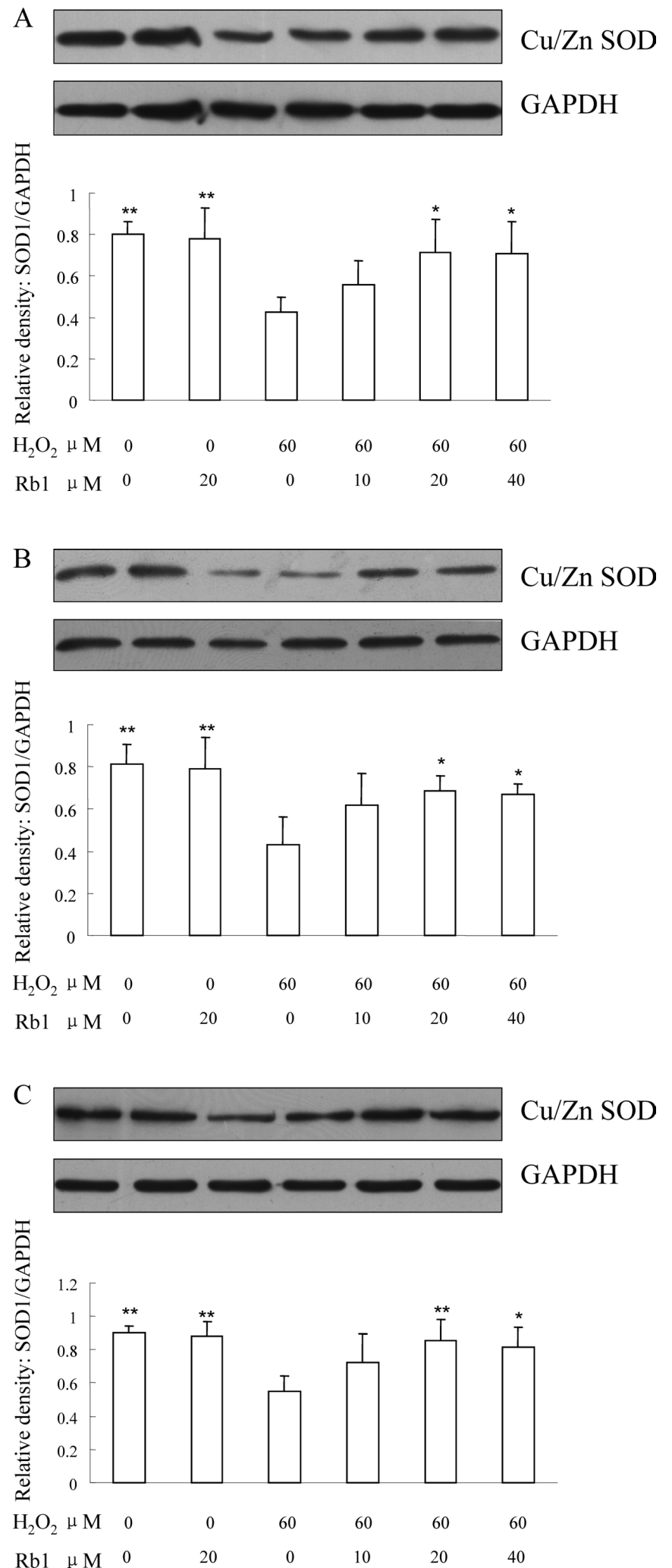

Fig. 5. Rb1 Promotes SOD1 Protein Expression in HUVECs. The Reversal Effect of $\mathrm{Rb} 1$ on $\mathrm{Cu} / \mathrm{Zn}$ SOD Protein Expression in $\mathrm{H}_{2} \mathrm{O}_{2}$-Induced Senescenced HUVECs in Indicated Time Points (A, 24 h; B, 48 h; C, 72 h) after Treatment

HUVECs were pretreated with indicated doses of Rb1 for $30 \mathrm{~min}$ before the administration of $60 \mu \mathrm{M} \mathrm{H}_{2} \mathrm{O}_{2}$. The medium was replaced with normal medium $1 \mathrm{~h}$ later and cultured for $24 \mathrm{~h}(\mathrm{~A}), 48 \mathrm{~h}(\mathrm{~B})$ or $72 \mathrm{~h}(\mathrm{C})$. Then the cells were collected and lysated. The protein level of SOD1 was evaluated by Western blot with SOD1 antibody. GAPDH served as loading control. Shown were representative blots of three independent experiments on $2-3$ passaged cells after separate primary cultures with similar results and expressed as means \pm S.E.M. $* p<0.05$, $* * p<0.01$ versus $60 \mu \mu_{\mathrm{M}} \mathrm{H}_{2} \mathrm{O}_{2}$ alone.
DCF fluorescence (Fig. 6D) whereas pre-treatment with $20 \mu \mathrm{mol} / 1 \mathrm{Rb} 1$ markedly inhibited the production of ROS induced by $\mathrm{H}_{2} \mathrm{O}_{2}$ (Fig. 6E).

\section{DISCUSSION}

Consistent with previous studies showing the protective effects of $\mathrm{Rb} 1$ on vascular cells against injury in vitro, ${ }^{12,18)}$ we report here that $\mathrm{Rb} 1$ reversed HUVECs senescence induced by $\mathrm{H}_{2} \mathrm{O}_{2}$ through modulating endogenous antioxidants and pro-oxidants products. Although intensive research has been focused on $\mathrm{Rb} 1$ regarding to its protective effect on different cell type damage including endothelial ${ }^{12,18)}$ and neural cell, ${ }^{19}$ few studies have investigated the potential anti-senescence or anti-aging role of $\mathrm{Rb} 1,{ }^{20)}$ especially for endothelial cells. Our findings were based on oxidative stress induced HUVECs senescence by using $\mathrm{H}_{2} \mathrm{O}_{2}$. In this system, after sublethal dose of $\mathrm{H}_{2} \mathrm{O}_{2}$ treatment, HUVECs exhibited typical senescent phenotypes which were confirmed by the morphology marker of SA- $\beta$-gal. Our data show that Rb1 reversed the senescent phenotypic changes. This is the first report to show a role of Rb1 in protecting cellular senescence in HUVECs.

It is known that some of ROS products are extremely unstable and metabolized rapidly via a delicate oxidative-antioxidative system. ${ }^{21}$ ) Thus it is not accurate to illustrate the extent of cell senescence or injury by a transient indicator. Since the free-radical theory of aging proposes that degenerative senescence is largely dependent on the cumulative effect of ROS, ${ }^{21}$ we examined ROS products within senescent cells by using a stable and metabolic product or long lived metabolic enzyme. Consistence with increased ROS production in the senescent HUVECs, the intracellular peroxidized end product MDA elevated in HUVECs, while the antioxidants SOD1 was defective in the senescent cells. These results support the free-radical theory of aging, ${ }^{5,21)}$ and prove that the model of $\mathrm{H}_{2} \mathrm{O}_{2}$-induced HUVECs senescence used in our experiments is suitable to characterize the anti-senescence function of Rb1. It is well known that SODs act as enzymes that catalyze the superoxide anion radical into hydrogen peroxide. ${ }^{13)}$ SOD is recognized as antioxidant defense enzyme and its abnormal expression is implicated in life span. $^{22)}$ Decreased level and activity of SOD after the administration of exogenous $\mathrm{H}_{2} \mathrm{O}_{2}$ is also reported in other $\mathrm{H}_{2} \mathrm{O}_{2}$ injury models. ${ }^{23,24)}$ It is supposed to be a negative feedback that endogenous SOD is reduced by an elevated level of exogenous $\mathrm{H}_{2} \mathrm{O}_{2}$. In addition, the decreased level and activity of SOD could result in the accumulation of superoxide anion radical in the cells which may be partly responsible for $\mathrm{H}_{2} \mathrm{O}_{2}$ induced injury and the increased level of lipid peroxidation showed in our study.

Interestingly, $\mathrm{Rb} 1$ was found to improve endothelial proliferation and decrease the production of superoxide anion in Hcy induced SVEC4 - 10 cells injury. ${ }^{12)}$ Here we described a specific type of cell injury, senescence, which is induced by $\mathrm{H}_{2} \mathrm{O}_{2}$ treatment. Furthermore, our data demonstrate that $\mathrm{Rb} 1$ exhibited antagonistic effects against $\mathrm{H}_{2} \mathrm{O}_{2}$-induced senescence. It is important to note that the change of SOD activity and MDA level was not perfectly coincident in HUVECs pretreated with different concentrations of Rb1, suggesting that the reduction of lipid peroxidation induced by $\mathrm{Rb} 1$ may also depend on other ROS scavenging system, not limited to 
A

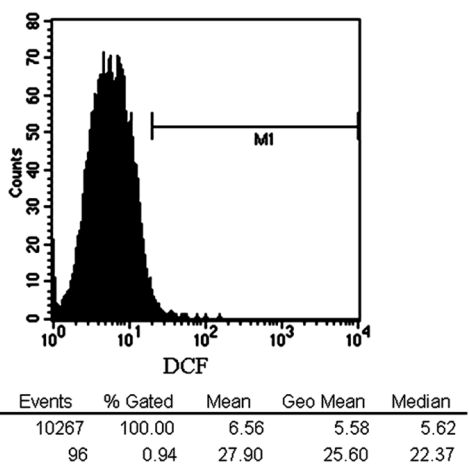

B
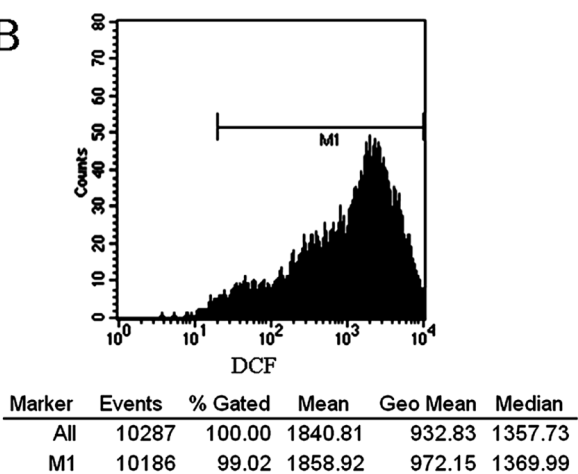

$\begin{array}{llllll}\text { M1 } & 10186 & 99.02 & 1858.92 & 972.15 & 1369.99\end{array}$

$\mathrm{C}$

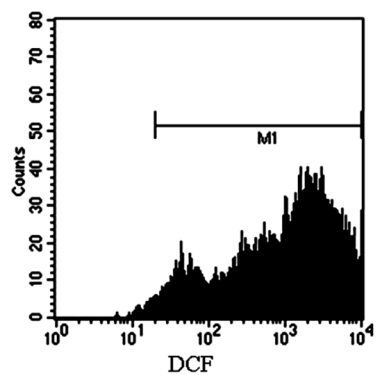

\begin{tabular}{rrrrrr} 
Marker Events & \% Gated & Mean & Geo Mean Median \\
\hline All & 10356 & 100.00 & 1976.96 & 841.60 & 1263.46
\end{tabular}

$\begin{array}{rrrrrr}\text { All } & 10356 & 100.00 & 1976.96 & 841.60 & 1263.46 \\ \text { M1 } & 10249 & 98.97 & 1997.44 & 877.77 & 1286.40\end{array}$
D

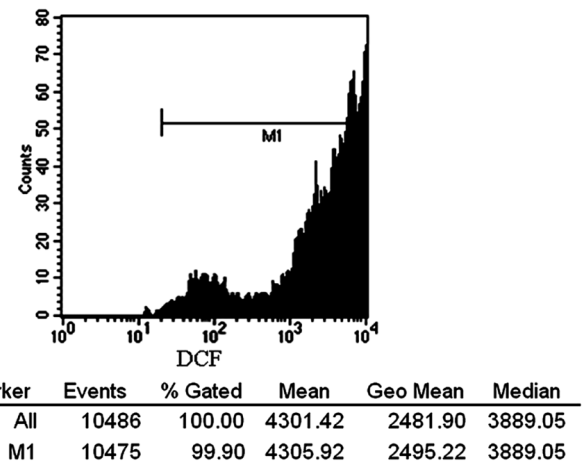

$\mathrm{E}$

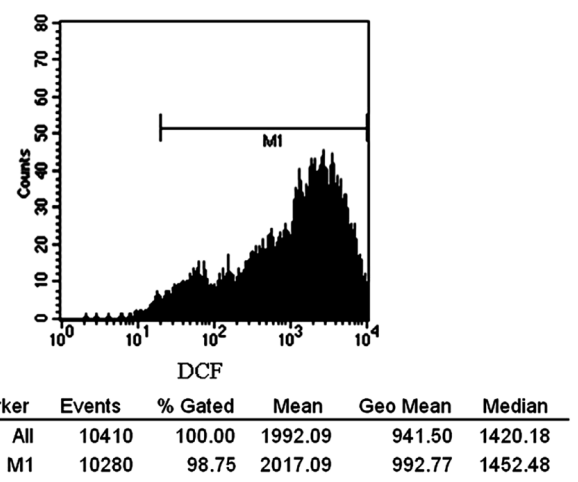

$\mathrm{F}$

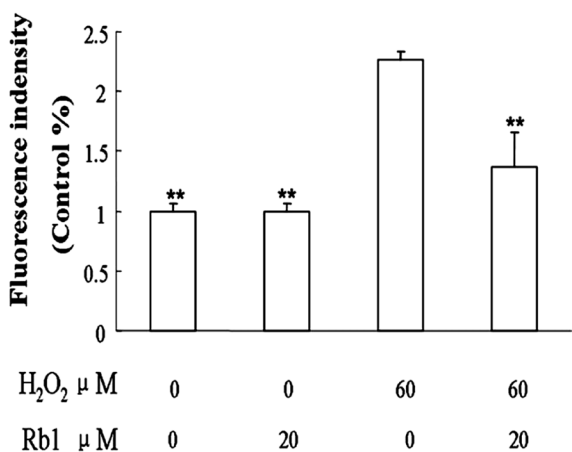

Fig. 6. $\mathrm{Rb} 1$ Antagonizes $\mathrm{H}_{2} \mathrm{O}_{2}$-Induced ROS Production in HUVECs

The fluorescence intensity was measured with a flow cytometer. (A) negative control (without $\mathrm{H}_{2} \mathrm{DCF}-\mathrm{DA}$ ); (B) blank control (without $\mathrm{H}_{2} \mathrm{O}_{2}$ ); (C) $20 \mu$ mol/1 Rb1 alone; (D) $60 \mu \mathrm{mol} / 1 \mathrm{H}_{2} \mathrm{O}_{2}$ treatment for $60 \mathrm{~min}$; (E) $60 \mu \mathrm{mol} / 1 \mathrm{H}_{2} \mathrm{O}_{2}$ treatment for 60 min plus pre-incubation with Rb1 for 30 min; (F) Effects of Rb1 on the production of intracellular ROS. "Marker" indicated a line separating regions on single parameter histograms that are treated statistically separate. "All" indicated all the area within (and on) the boundary. "M1" indicated positive area which is set according to the blank control. The values were expressed as percentages of the fluorescence intensity. $* * p<0.01$ versus $60 \mu \mathrm{M} \mathrm{H}_{2} \mathrm{O}_{2}$ alone. The shown graph was representative of three independent experiments on $2-3$ passaged cells after separate primary cultures with similar results.

SOD1. Indeed, Rb1 has been shown to upregulate the expression of catalase, an enzyme that catalyzes the conversion of hydrogen peroxide to water and oxygen ${ }^{25)}$ and glutathione peroxidase (GSH-Px), an enzyme that catalyzes the breakdown of hydrogen peroxide and organic hydroperoxides, ${ }^{26}$ ) affect heme oxygenase (HO-1) expression and suppress p47phox expression. ${ }^{27-29)}$ Furthermore, a recent study showed that $\mathrm{Rb} 1$ protected liver from ischemia-reperfusion injury through upregulating NO concentration and SOD1 activity and reducing MDA level. ${ }^{30)}$

Although Rb1 works as a direct scavenger or increases the level of antioxidants to indirectly scavenge the ROS, ${ }^{27-30}$ ) our results in this study provide evidence that $\mathrm{Rb} 1$ is more likely to increase the antioxidant and act as an indirect ROS scavenger: (1) Rb1 mitigates the oxidative stress via reducing the stable metabolic molecular MDA level and decreasing the intracellular ROS level in $\mathrm{H}_{2} \mathrm{O}_{2}$-induced senescent HUVECs. (2) Enhanced SOD activity and expression are observed after $\mathrm{Rb} 1$ pre-treatment in $\mathrm{H}_{2} \mathrm{O}_{2}$-induced senescent HUVECs. The present study is performed on the well characterized model of $\mathrm{H}_{2} \mathrm{O}_{2}$-induced senescence which is based on arrested cell growth caused by imbalanced ROS scavenging. In our study, the correlation of the activity and expression of SOD and the production of ROS is well coincident in the senescent model. By analyzing the changes of SOD, ROS (or stable metabolic substance, MDA), and senescent phenotype, it is clearly indicated that Rb1 protects HUVECs from $\mathrm{H}_{2} \mathrm{O}_{2}$-induced senescence through regulating the redox status.

In conclusion, our data demonstrate that ginsenoside $\mathrm{Rb} 1$ 
modulates redox status such as upregulating SOD1 expression, scavenging ROS, and decreasing the peroxidation to prevent the cellular senescence in HUVECs.

Acknowledgement This work was supported by the Grants from Major State Basic Research Development Program (grant number 2005CB523305); Natural Science Foundation of Guangdong Province (Grant number 8151008901000209); and Science and Technology Planning Project of Guangdong Province (Grant number 2007 B060401024).

\section{REFERENCES}

1) Lakatta E. G., Levy D., Circulation, 107, 139-146 (2003).

2) White N. K., Edwards J. E., Dry T. J., Circulation, 1, 645-654 (1950).

3) Csiszar A., Wang M., Lakatta E. G., Ungvari Z., J. Appl. Physiol., 105, 1333-1341 (2008).

4) Sussman M. A., Anversa P., Annu. Rev. Physiol., 66, $29-48$ (2004).

5) Harman D., J. Gerontol., 11, 298-300 (1956).

6) He T., Joyner M. J., Katusic Z. S., Microvasc. Res., 78, 447-452 (2009).

7) Liu Y., Kern J. T., Walker J. R., Johnson J. A., Schultz P. G., Luesch H., Proc. Natl. Acad. Sci. U.S.A., 104, 5205-5210 (2007).

8) Oeseburg H., de Boer R. A., Buikema H., van der Harst P., van Gilst W. H., Silljé H. H., Arterioscler. Thromb. Vasc. Biol., 30, 1407-1414 (2010).

9) Imanishi T., Hano T., Nishio I., J. Hypertens., 23, $97-104$ (2005).

10) Cai B. X., Jin S. L., Luo D., Lin X. F., Gao J., Biol. Pharm. Bull., 32, 837-841 (2009).

11) Cheng Y., Shen L. H., Zhang J. T., Acta Pharmacol. Sin., 26, 143-
149 (2005)

12) Ohashi R., Yan S., Mu H., Chai H., Yao Q., Lin P. H., Chen C., J. Surg Res., 133, 89-94 (2006).

13) Zelko I. N., Mariani T. J., Folz R. J., Free Radic. Biol. Med., 33, 337 349 (2002)

14) Crapo J. D., Oury T., Rabouille C., Slot J. W., Chang L. Y., Proc. Natl. Acad. Sci. U.S.A., 89, $10405-10409$ (1992).

15) Parslow R. A., Sachdev P., Salonikas C., Lux O., Jorm A. F., Naidoo D., J. Hum. Hypertens., 19, 219-226 (2005).

16) Bandin B., Bruneel A., Bosselut N., Vaubourdolle M., Nat. Protoc., 2, $481-485$ (2007).

17) Dimri G. P., Lee X., Basile G., Acosta M., Scott G., Roskelley C., Medrano E. E., Linskens M., Rubelj I., Pereira-Smith O., Peacocke M. Campisi J., Proc. Natl. Acad. Sci. U.S.A., 92, 9363-9367 (1995).

18) Xu Z., Lan T., Wu W., Wu Y., J. Vasc. Surg., 53, 156-164 (2011).

19) Qian Y. H., Han H., Hu X. D., Shi L. L., Neurol. Res., 31, 663-667 (2009).

20) Kang T. H., Park H. M., Kim Y. B., Kim H., Kim N., Do J. H., Kang C., Cho Y., Kim S. Y., J. Ethnopharmacol., 123, 446-451 (2009).

21) Finkel T., Holbrook N. J., Nature (London), 408, 239-247 (2000).

22) Landis G. N., Tower J., Mech. Ageing Dev., 126, 365-379 (2005).

23) Liu C.-S., Chen N.-H., Zhang J.-T., Phytomedicine, 14, 492-497 (2007).

24) Shang Y. Z., Qin B. W., Cheng J. J., Miao H., Phytother. Res., 20, 53 57 (2006).

25) Chelikani P., Fita I., Loewen P. C., Cell. Mol. Life Sci., 61, 192-208 (2004).

26) Brigelius-Flohé R., Free Radic. Biol. Med., 27, 951-965 (1999).

27) Deng H. L., Zhang J. T., Chin. Med. J., 104, 395-398 (1991).

28) Hwang Y. P., Jeong H. G., Toxicol. Appl. Pharmacol., 242, 18-28 (2010).

29) Xie X. S., Liu H. C., Yang M., Zuo C., Deng Y., Fan J. M., Chin. J. Integr. Med., 15, 133-140 (2009).

30) Guo Y., Yang T., Lu J., Li S., Wan L., Long D., Li Q., Feng L., Li Y., Life Sci., 88, 598-605 (2011). 